\title{
Establishment of Mouse Embryonic Stem Cell and Effects of Herbal Medicine on Induction of Cardiomyocyte Differentiation
}

\author{
Ji Hyang Lee and Eun Lee* \\ Department of Pharmaceutical Engineering, Sangji University, Wonju-si 220-702, Korea
}

\begin{abstract}
This study was conducted to investigate the effects of Woohwangcheungsimweun (ox bezoar), deer antlers, and wild ginseng on induction of cardiomyocyte differentiation using the established mouse embryonic stem (ES) cells. The expression of atrial natriuretic peptide (ANP) was highest in Woohwangcheungsimweun treatment group. The expression of rabbit anti-GATA-4(GATA-4) and troponin (TnI) were highest in wild ginseng and Woohwangcheungsimweun treatment groups, respectively. Fluorescence activated cell sorting (FACS) analysis showed that the expression of ANP was highest in Dimethyl sulfoxide(DMSO) and Woohwangcheungsimweun treatment groups. The expression of GATA-4 was relatively high in wild ginseng treatment group. The expression of TnI was highest in Woohwangcheungsimweun treatment group. In the gene expression analysis, DMSO greatly inhibited GATA-4 expression to $25 \%$ of control. Woohwangcheungsimweun treatment caused to increase cTnI and cardiac ANP expression significantly. Wild ginseng extract upregulated GATA-4 gene expression. In conclusion, DMSO widely used as cardiomyocyte differentiation inducer did not show significant effects on the expression of ANP, GATA-4 and TnI in this study. Woohwangcheungsimweun showed upregulation of ANP and TnI expression. Wild ginseng extract showed greater effects than DMSO on GATA-4 expression. These results might suggest that the combination of Woohwangcheungsimweun and wild ginseng extract treatment can be expected to increase expressions of all three genes.
\end{abstract}

Key words - Mouse ES cell, Cardiomyocyte, DMSO, Woohwangcheungsimweun, Deer antlers, Wild ginseng

\section{Introduction}

Since Evans and Kaufman (1981) first isolated an embryonic stem (ES) cell from the blastocyst embryo of a mouse and in vitro culture of ES cells succeeded (Thomson et al., 1995; Bongso, 1994), induction of differentiation to a specific cell from the ES cell (Hirashima al., 1999; Kawasaki et al., 2000; Kramer et al., 2000; Lee et al., 2000; Nakayama et al., 2000; Soria et al., 2000; Yamane al., 1999) were studied by many researchers.

The induction of differentiation into a specific cells has recently been extensively studied. As Reubinoff and others (2000) were successful in differentiating a neural progenitor cells from hES cells by applying the culturing process of the mouse ES cell, it was possible to utilize the ES cell as a tool for treatment of human diseases. However, more studies for the separation and cultivation, characterization, mass production

${ }^{*}$ Corresponding author. E-mail : elee@sangji.ac.kr and induction of ES cell differentiation are required.

Woohwangcheungsimweun, deer antlers and wild ginseng have been applied to prevent and cure the heart diseases and their clinical efficacy has been highly estimated in clinical aspects. These oriental medicines may contain functional components to stimulate heart function.

Therefore, as part of basic research to develop functional substance related to the differentiation of the ES cell into the cells of specific tissues, we have isolated mouse embryonic stem cells and then examined the effect of medical herb (Woohwangcheungsimweun, deer antlers and wild ginseng extract) on the induction of ES cell differentiation into the cardiomyocytes.

\section{Materials and Methods}

\section{Isolation and culturing of ES cell}

Female BDF1 mice ( $\mathrm{C}_{57} \mathrm{BL}$ x DBA. 6 10 weeks old) were hyperstimuled ant then mated with males in individual cage. 
Mice were killed by cervical dislocation, ovaries removed and zygotes of 1-cell stage collected. All procedures used in this study were performed in accordance with the Guide for the Care and Use of Laboratory animals and the work was approved by the Ethics Committee of the Faculty. Culture medium was Modified Basal XI media (Modified Cleavage medium, Sage Inc.) with $10 \%$ Serum Substitute Supplement (SSS, Irvine Sci. 92705) under paraffin oil for further culture. Embryos were cultured when they had developed into expanded blastocysts or early hatching stage in an incubator at $37^{\circ} \mathrm{C}$ in a humidified atmosphere of $5.0 \% \mathrm{CO}_{2}$ for $5-6$ days.

The mouse embryonic feeder fibroblasts (MEF) cells were prepared from ICR mouse embryos at 13.5-16.5 days post-coitum. The culture medium was Dulbecco's modified Eagle's medium (DMEM, Gibco-BRL, 11995). The cells were cultured in $60-\mathrm{mm}$ culture dish (Flacon) at $37^{\circ} \mathrm{C}, 5.0 \%$ $\mathrm{CO}_{2}$ incubator until confluency, and then resuspended in $1 \mathrm{ml}$ freezing medium. Freezing medium contained 10\% dimethyl sulfoxide (DMSO) and $0.5 \sim 1 \times 10^{7} \mathrm{cell} / \mathrm{ml}$. The frozen feeder aliquots were thawed and cultured until confluency and treated with $10 \mu \mathrm{g} / \mathrm{ml}$ mitomycin C (Sigma) in MEF culture medium with $20 \% \mathrm{FBS}$ for 2 hours in $37^{\circ} \mathrm{C}$, washed three times with phosphate-buffered saline (PBS), and plated onto a coated dish (4 well dish; Nunc) without gelatin treatment. The MEF cells were obtained at passage 3 5 and were passed four more times before freezing in liquid nitrogen. Frozen vials containing ES cells were thawed and passed three more times before differentiation.

To characterize ES cells alkaline phosphatase activity, Immunocytochemical test (SSEA-1 and Oct4-ES cell marker sample kit, Chemicon), teratoma formation using nude mouse (nu/nu B/C, 36 42 days old, non-obese diabetic-severe combined immunodeficiency) and general histomorphological test were examined.

\section{Induction of differentiation into cardiacmyocytes}

For induction of differentiation, embryoid bodies (EBs) were formed using hanging drops ( $25 \mu \mathrm{L} / \mathrm{drop}, 10^{3}$ cells/drop) and cultured in the medium containing $1 \%$ DMSO, $1 \%$ Woohwangcheungsimweun (K. co. Korea), 1\% deer antlers, $1 \%$ wild ginseng extract and $0.1 \mathrm{mg} / \mathrm{ml}$ wild ginseng powder on coated 4 well-dish without gelatin treatment (4 5 EBs/ well) for 5 days until formation of beating cell cluster. For preparation of natural products, $500 \mathrm{~g}$ of deer antlers and $500 \mathrm{~g}$ of wild ginseng were extracted with $\mathrm{MeOH} 3$ times for 5 hours each in cooling water reflux cisten, and then concentrated under decompression. Final yield was approximately $120 \mathrm{mg}$.

Immunocytochemical analysis of cardiacmyocyte was carried out on day 9 using rabbit anti-atrial natriuretic peptide (ANP, 1:500, Chemicon), and rabbit anti-GATA-4 (GATA-4, 1:100, chemicon, AB4132) polyclonal antibody and mouse anti-human cardiac Troponin I monoclonal antibody (cTn1, 1:1000, Chemicon). Fluorescence-activated cell sorting (FACS) analysis, beating rate and reverse transcription-polymerase chain reaction (RT-PCR) analysis were also performed for analysis of cardiocmyocyte differentiation.

Beating ratio of $\mathrm{EB}$ (number of beating $\mathrm{EB} / 5 \mathrm{EBs}$ plated) of each treatment group was measured at day 5 after plating of 5 EBs per well. The number of beating EB was measured 8 times and mean values were calculated.

Total RNA was extracted from ES cells and EBs using TRI reagent (Sigma) according to the manufacturer's instructions.

Table 1. The primers used in RT-PCR, the nucleotide position and the estimated size of the amplified fragments

\begin{tabular}{|c|c|c|c|}
\hline Gene & Primers & Position & $\begin{array}{c}\text { Expect size } \\
\text { (Known gene) }\end{array}$ \\
\hline TnI & $\begin{array}{l}\text { Forward GATGGAACGAGAGGCAGAAG } \\
\text { Reverse CССТCAAACTTTTTCTTGCG }\end{array}$ & $\begin{array}{l}183-202 \\
632-613\end{array}$ & $\begin{array}{l}\text { 450bp } \\
\text { (Tnni3) }\end{array}$ \\
\hline ANP & $\begin{array}{l}\text { Forward AACCTGCTAGACCACCTGGA } \\
\text { Reverse GGAAGCTGTTGCAGCCTAGT }\end{array}$ & $\begin{array}{l}121-140 \\
445-426\end{array}$ & $\begin{array}{l}325 \mathrm{bp} \\
\text { (Nppa) }\end{array}$ \\
\hline GATA-4 & $\begin{array}{l}\text { Forward CCGTCTACGTGCCACTCC } \\
\text { Reverse GTGATAGAGGCCACAGGCAT }\end{array}$ & $\begin{array}{l}106-123 \\
729-710\end{array}$ & $\begin{array}{l}624 \mathrm{bp} \\
\text { (ATA4) }\end{array}$ \\
\hline$\beta$-actin & $\begin{array}{l}\text { Forward TGTTACCAACTGGGACGACA } \\
\text { Reverse AAGGAAGGCTGGAAAAGAGC }\end{array}$ & $\begin{array}{l}225-244 \\
797-778\end{array}$ & $\begin{array}{l}573 \mathrm{bp} \\
\text { (Actb) }\end{array}$ \\
\hline
\end{tabular}


First strand cDNA was synthesized from $5 \mathrm{mg} / \mathrm{ml}$ total RNA using M-MLV Reverse transcriptase kit (Promega). Complementary DNAs were subjected to PCR amplification with primers specific for mouse cardiac genes (Table 1). PCR was performed in a reaction volume of $30 \mu \mathrm{L}$ with $2.5 \mathrm{mM}$ dNTP mixture Ex-Taq polymerase (2.5 units, TaKaRa), $0.2 \mu$ $\mathrm{M}$ forward and reverse primers, and $1 \mu \mathrm{L}$ cDNA template. The profile for $\mathrm{PCR}$ reaction was $94^{\circ} \mathrm{C}$ for $5 \mathrm{~min}$, followed by 35 cycles of denaturation at $94^{\circ} \mathrm{C}$ for $30 \mathrm{sec}$, annealing at $57 \sim 60^{\circ} \mathrm{C}$, depending on the melting temperature of the primer sequence, for $30 \mathrm{sec}$, and extension at $72^{\circ} \mathrm{C}$ for $45 \mathrm{sec}$, then 10 $\min$ at $72^{\circ} \mathrm{C}$ for the final extension. The PCR products were size fractionated by electrophoresis on a $1.5 \%$ agarose gel containing $0.1 \mathrm{mg} / \mathrm{ml}$ ethidium bromide and photographed with BioRad Gel Imaging System using a GeneRuler DNA ladder mix as a size marker (Fermentas). Statistical analysis was performed by students' t-test (SPSS 13.0). The probability at $\mathrm{p}<0.05$ was considered significant.

\section{Results and Discussion}

\section{Identification of the isolated and cultured mouse embryonic stem cell}

For characterization of the established mouse embryonic stem cell, alkaline phosphatase activity, immunocytochemical analysis (SSEA-1 and Oct-4 cell markers), teratoma formation using nude mouse and histochemical test were conducted. Alkaline phosphatase activity about $100 \%$ of cell colony were positive for alkaline phosphatase. Immunocytochemical analysis demonstrated that most of colonies were positive for SSEA-1 and Oct-4 (Fig. 1).

Established ES cells were injected to a nude mouse and teratoma formation was observed (Fig. 2). Histological examination of teratoma demonstrated the presence of endoderm, mesoderm and ectoderm, suggesting plulipotency of this ES cell line.

\section{Induction of differentiation into cardiomyocytes}

We investigated the effect of functional natural products on the induction of ES cell differentiation into cardiomyocytes.

As shown in Fig. 3 EB, Beating was observed in EB outgrowth suggesting ES cells were induced to differentiate into cardiomyocytes.

To examine protein expression, immunohistochemical analysis was performed using ANP, GATA-4 and TnI antibodies.

Expression of these proteins were confirmed by this method (Figs. 4, 5 and 6). Immunocytochemical test for ANP


Fig. 1. Immunocytochemistry test of SSEA-1 and Oct-4 in ES cells. Scale bar $=100 \mu \mathrm{m}$.

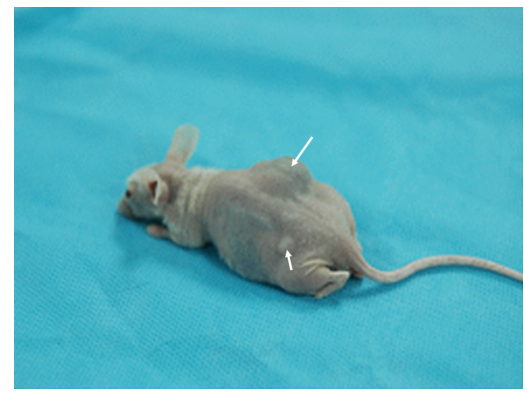

Fig. 2. Formation of teratoma on 35 days after injection on ES cell in the nude mouse.
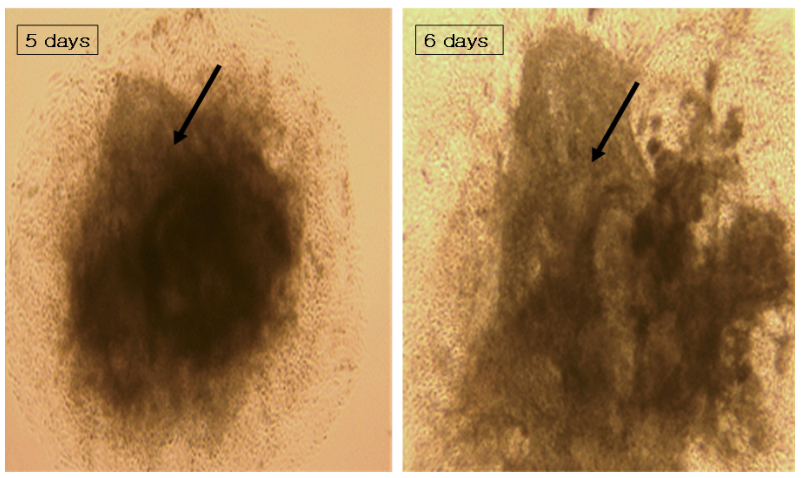

Fig. 3. Beating cell clusters (arrow) of cardiomyocyte on 5 and 6 days after hanging drop culture. 
as shown in Fig 4. Showed green fluorescence in all treatment groups, indicating that ES cells were differentiated into cardiomyocytes. However, expression was different among treatment groups. The intensity of green fluorescence radiation between control group and deer antlers treatment group was similar. The intensity of control and deer treatment groups were weak, compared with those in DMSO treatment group, Woohwangcheungsimweun treatment group, wild ginseng extract treatment group and wild ginseng powder treatment groups. The intensity was greatest in Woohwangcheungsimweun treatment group.

Expression of GATA4 are shown in Fig. 5. Intensity of green fluorescence was lowest in DMSO treatment group among all the treatment groups. Intensity in deer antlers
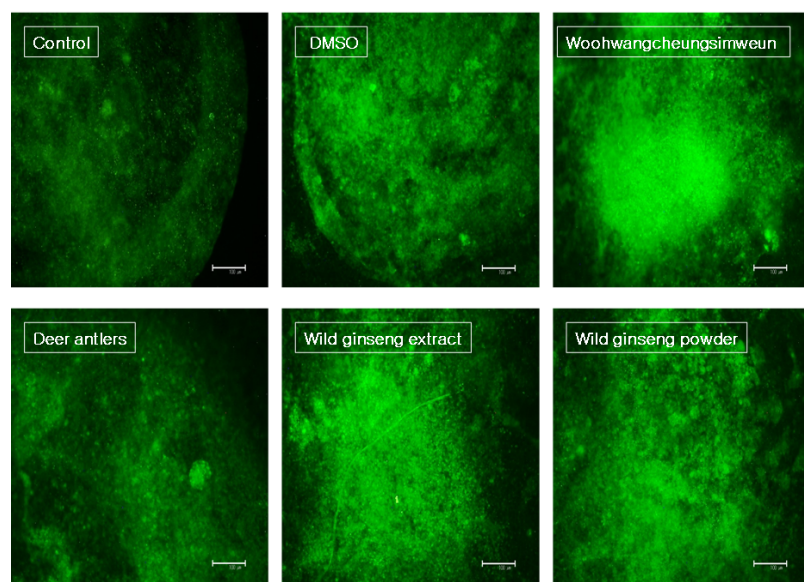

Fig. 4. Immunocytochemistry test of ANP in the differentiation cell.
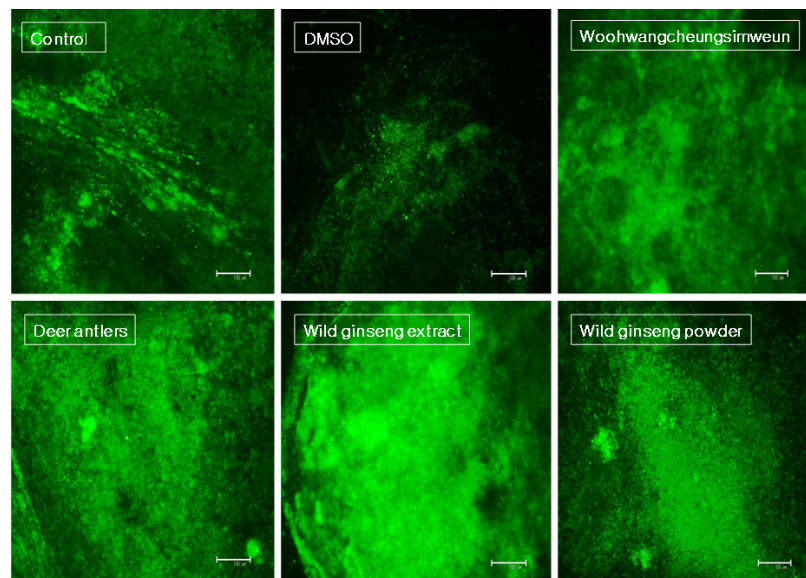

Fig. 5. Immunocytochemistry test of GATA-4 in the differentiation cell.
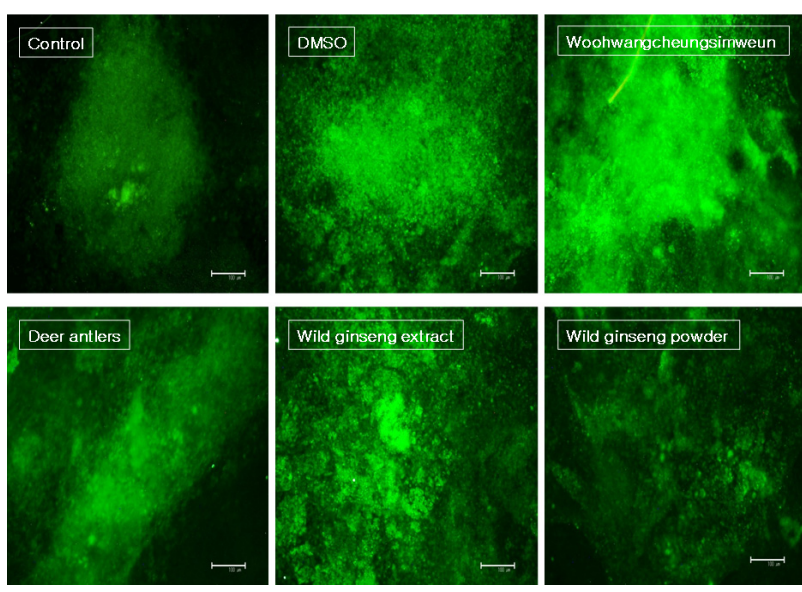

Wikd ginseng powder

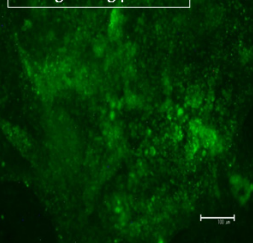

Fig. 6. Immunocytochemistry test of cTnI in the differentiation cell.
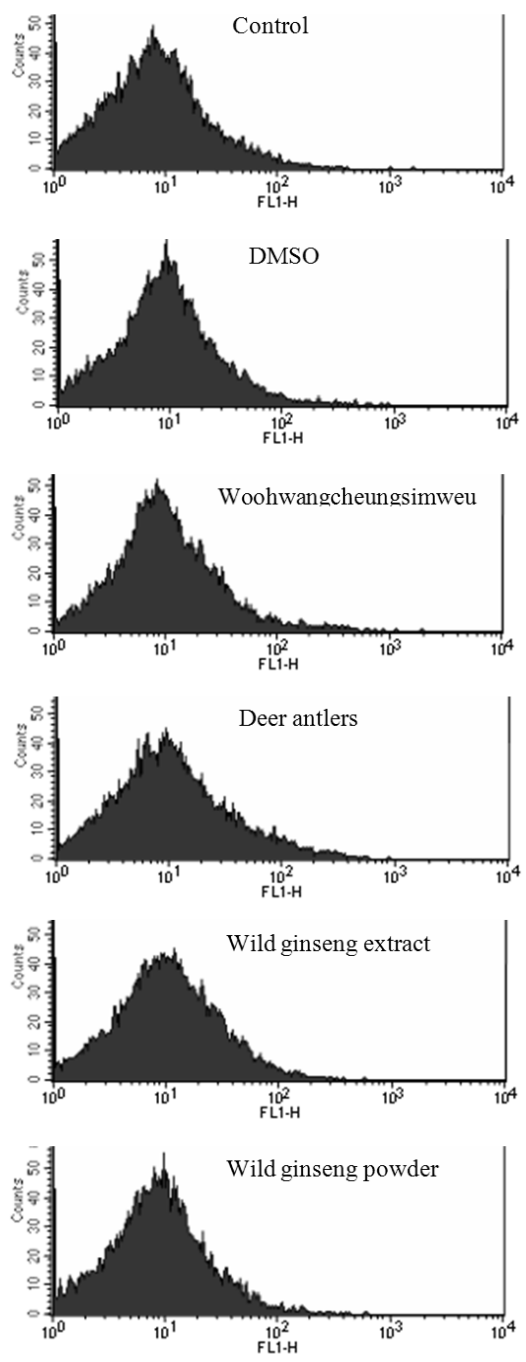

Fig. 7. FACS analysis of ANP concentration in the differentiated cardiomyocyte. 
treatment group, Woohwangcheungsimweun treatment group and wild ginseng powder treatment group were similar with that in control group. The intensity were higher in wild ginseng extract treatment group than any other treatment groups.

Expression of TnI are shown in Fig. 6. Intensity of green fluorescence radiation were highest in Woohwangcheungsimweun treatment group. Intensity of DMSO treatment group and wild ginseng extract treatment group were greater than those in control group. Intensity in wild ginseng powder treatment group were less than that in control group.

To further examine differentiation into cardiomyocyte quantitatively, fluorescence activated cell sorting (FACS)
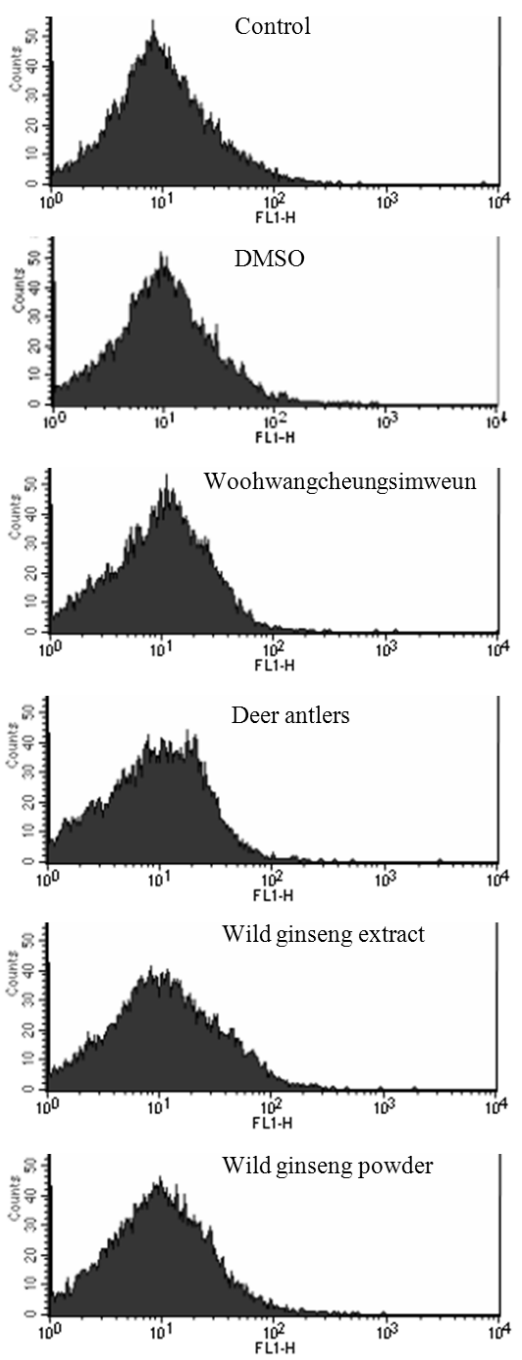

Fig. 8. FACS analysis of GATA-4 concentration in the differentiated cardiomyocyte. analysis was performed for ANP, GATA-4 and TnI. FACS analysis for ANP (Fig. 7) demonstrated slight increase of cells with high expression $1 \times 10^{2}$ (FLI-H) (M3) in Woohwangcheungsimweun and deer antlers treated groups. High expression was also observed in Woohwangcheungsimweun treatment in RT-PCR. FACS analysis for GATA-4 (Fig. 8) demonstrated increase of cells with intensity of higher than $4 \times 10^{2}$ (FLI-H), consistent with RT-PCR result. FACS analysis for TnI (Fig. 9) demonstrated no obvious difference in all treatments.

The ratio of beating EB at day 5 after plating onto medium containing each natural products is shown in Table 2. The ratio of beating EB ranged from $72 \%$ to $85 \%$. The ratios of
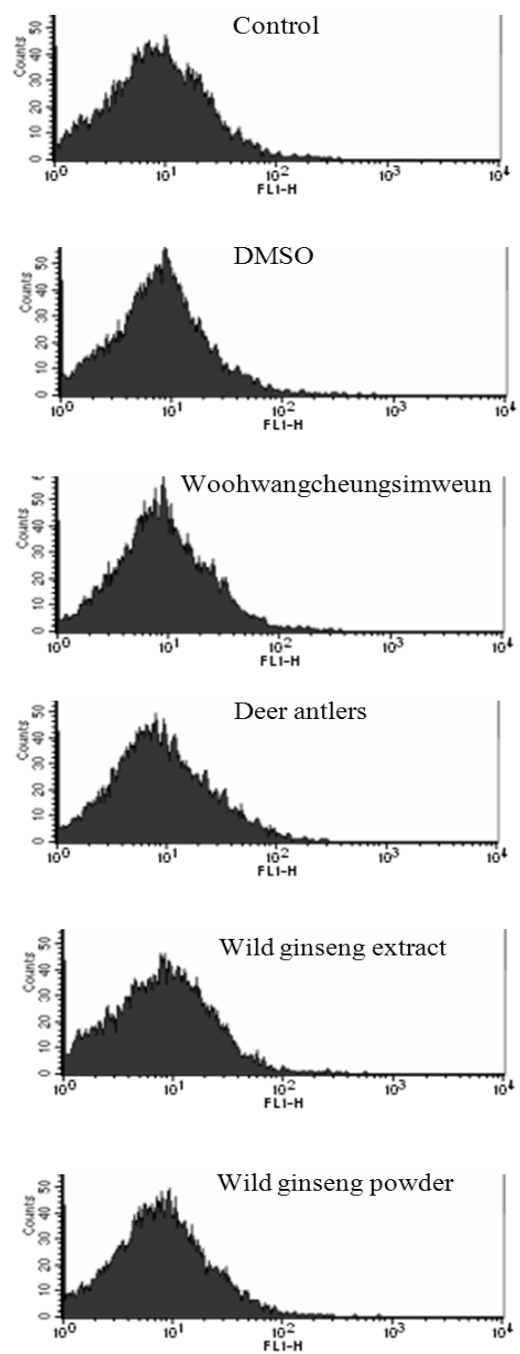

Fig. 9. FACS analysis of cTnI concentration in the differentiated cardiomyocyte. 
Table 2 . The ratio of beating embryoid bodies on day 5 after plating onto medium containing each natural products

\begin{tabular}{cc}
\hline \hline Treatment & Ratio (\%) of beating EB \\
\hline Control & $72.28 \pm 19.86^{\dagger}$ \\
DMSO & $77.34 \pm 15.27^{\dagger}$ \\
Woohwangcheungsimweun & $85.14 \pm 17.38^{\dagger}$ \\
Deer antlers & $81.65 \pm 10.21^{\dagger}$ \\
Wild ginseng extract & $79.36 \pm 14.24^{\dagger}$ \\
Wild ginseng dry powder & $82.08 \pm 12.75^{\dagger}$ \\
\hline
\end{tabular}

${ }^{\dagger}$ Not significantly different $(\mathrm{P}<0.05)$.

${ }^{*}$ Counting test of beating EB was performed 8 times for the ratio of beating embryoid bodies NO./ 5 embryoid bodies.

beating EB in Woohwangcheungsimweun treatment group, deer antlers treatment group and wild ginseng powder treatment group appeared to be higher than in control group, but there was no significant difference.

The results of RT-PCR analysis for ANP, GATA-4 and $\mathrm{TnI}$ in the differentiated cardiomyocytes are shown in Fig. 10. TnI and ANP gene expressions were higher in Woohwangcheungsimweun treated group compared to other treatment groups. GATA-4 gene expression was the highest in wild

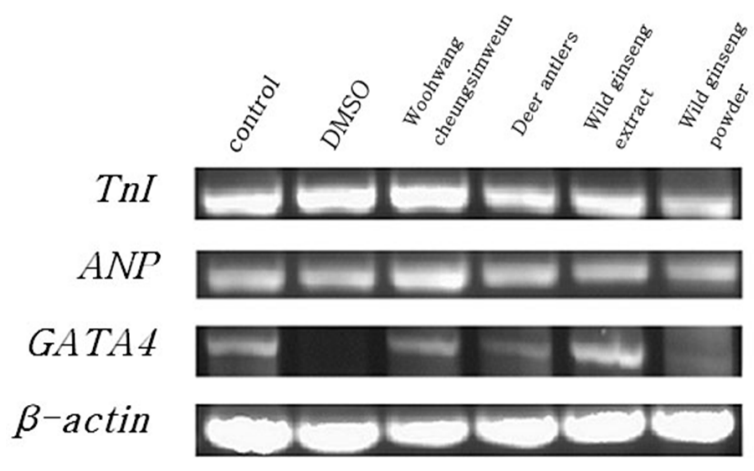

Fig. 10. RT-PCR analysis for specific gene expressions.

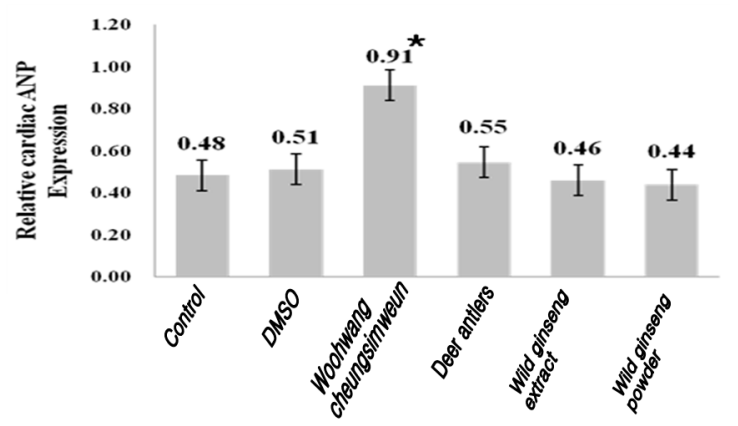

Fig. 11. The ratio of ANP/ b-actin in RT-PCR gene expression. $(\star: \mathrm{P}<0.05)$ ginseng extract treatment group and the lowest in DMSO treatment group. Relative expression of ANP, GATA-4 and TnI normalized by $\beta$-actin as shown in Figs. 11, 12 and 13, DMSO had no effect on the expression of cardiac ANP and GATA-4 genes, which are indicator genes for cardiac differentiation. DMSO, however, suppressed the GATA-4 gene expression. Woohwangcheungsimweun treatment induced

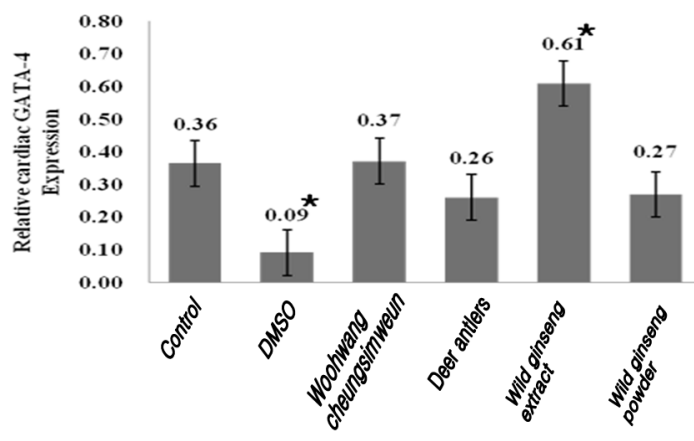

Fig. 12. The ratio of GATA-4/ b-actin in RT-PCR gene expression. $(\star: \mathrm{P}<0.05)$

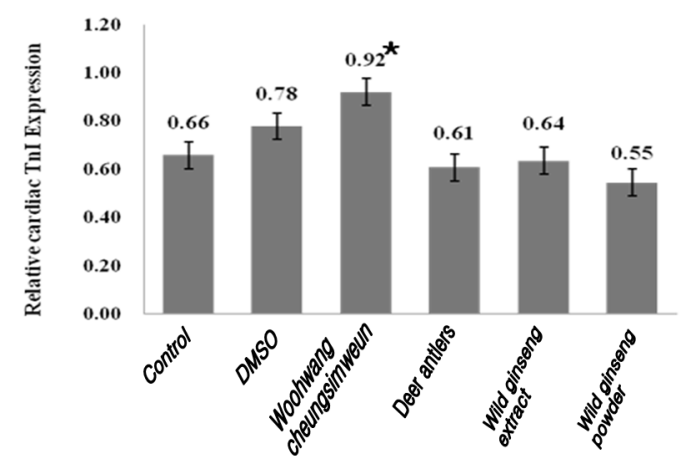

Fig. 13. The ratio of TnI/ b-actin in RT-PCR gene expression. $(\star: \mathrm{P}<0.05)$ 
TnI and cardiac ANP expressions significantly. GATA-4 gene expression was increased in wild ginseng extract treatment.

These results demonstrate that DMSO, currently widely used as cardiomyocyte differentiation inducer, does not have significant effect on ANP, GATA-4 and TnI gene expressions. On the other hand, Woohwangcheungsimweun or wild ginseng extract as herb medicines have greater effects than DMSO. Effect of induction of ANP and TnI by Woohwangcheungsimweun, and GATA-4 by wild ginseng extract were also observed by FACS analysis and showed good agreement. Combination of Woohwangcheungsimweun and wild ginseng extract treatment need to be investigated further.

\section{Literature Cited}

Bongso, A., C.Y. Fong, S.C. Ng and S. Ratnam. 1994. Isolation and culture of inner cell mass cells from human blastocysts. Hum. Reprod. 9:2110-2117.

Evans, M.J. and M.H. Kaufman. 1981. Establishment in culture of pluripotential cells from mouse embryos. Nature 292: 154-156.

Hirashima, M., H. Kataoka, S. Nishikawa, N. Matsuyuoshi and S. Nishikawa. 1999. Maturation of embryonic stem cells into endothelial cells in an in vitro model vasculogenesis. Blood 93:1253-1263.

Kawasaki, H., K. Mizuseki, S. Nishikawa, S. Kaneko, Y. Kuwana, S. Nakanishi, S.I. Nishikawa and Y. Sasai. 2000. Induction of midbrain dopaminergic neurons from ES cells by stromal cell derived inducing activity. Neuron 28:31-40. Kramer, J., C. Hegert, K. Guan, A.M. Wobus, P. K. Müller and J. Rohwedel. 2000. Embryonic stem cell-derived chondrogenic differentiation in vitro: activation by BMP-2 and BMP-4. Mech. Dev. 92:193-205.

Lee, S.H., N. Lumelsky, L. Studer, J.M. Auerbach and R.D. McKay. 2000. Efficient generation of midbrain and hindbrain neurons from mouse embryonic stem cells. Nat. Biotechnol. 18:675-679.

Nakayama, N., J. Lee and L. Chiu. 2000. Vascular endothelial growth factor synergistically enhances bone morphogenetic protein-4-dependent lymphohematopoietic cell generation from embryonic stem cells in vitro. Blood 95:2275-2283.

Reubinoff B.E, M.F. Pera and C.Y. Fong, A. Trounson and A. Bongso. 2000. Embryonic stem cell lines from human blastocysts: somatic differentiation in vitro. Nat. Biotechnol 18: 399-404.

Soria, B., E. Roche, G. Berná, T. León-Quinto, J.A. Reig and F. Martín. 2000. Insulin-secreting cells derived from embryonic stem cells normalize glycemia in streptozotocin-induced diabetic mice. Diabetes 49:157-162.

Thomson J.A, J. Kalishman, T.G. Golos, M. Durning, C.P. Harris, R.A. Becker and J.P. Hearn. 1995. Isolation of a primate embryonic stem cell line. Proc. Natl. Acad. Science USA 92:7844-7848.

Yamane, T., H. Hayashi, M. Mizoguchi, H. Yamazaki and T. Kunisada. 1999. Derivation of melanocytes from embryonic stem cells in culture. Dev. Dyn. 216: 450-458. 